\title{
Psychometric properties of a new self-report measure of medical student stress using classic and modern test theory approaches
}

\author{
Matthew J. Mosquera ${ }^{*} \mathbb{B}$, Aaron Kaat ${ }^{2}$, Melinda Ring ${ }^{3}$, Gaurava Agarwal ${ }^{4}$, Sydney Glickson ${ }^{2}$ \\ and David Victorson ${ }^{2 *}$
}

\begin{abstract}
Background: Medical students face significantstressors related to the intense rigors of their training and education. Accurate measurement of their stress is important to quickly identify, characterize and ameliorate these challenges. Existing measures have limitations that modern measurement approaches, such as item response theory (IRT), are able to address. This study presents the calibration and validation of a new IRT-based measure called the Medical Student Stress Scale (MSSS).

Methods: Following rigorous measurement development procedures described elsewhere, the authors created and tested a pool of 35 items with 348 1st - 4th year medical students along with demographic and external validity measures. Psychometric analysis included exploratory and confirmatory factor analyses, IRT modeling, and correlations with legacy measures.

Results: Of the original 35 items, 22 were retained based on their ability to discriminate, provide meaningful information, and perform well against legacy measures. The MSSS differentiated stress scores between male and female students, as well as between year in school.

Conclusion: Developed with input from medical students, the MSSS represents a student-centered measurement tool that provides precise, relevant information about stress and holds potential for screening and outcomes-related applications.
\end{abstract}

Keywords: Stress, Medical student, Measurement, Item response theory

\section{Background}

It is widely understood that medical school can be a very stressful experience that is different from other forms of life stress. This includes exposure to death and human suffering, ethical conflicts, adjustment to the pressures of the medical school environment, student abuse, personal

\footnotetext{
${ }^{*}$ Correspondence: mjmosquera@partners.org;

d-victorson@northwestern.edu

${ }^{1}$ Department of Psychiatry, Brigham and Women's Hospital, Harvard Medical School, 60 Fenwood Avenue, Boston, MA 02115, USA

${ }^{2}$ Department of Medical Social Sciences, Northwestern University Feinberg School of Medicine, Chicago, IL, USA

Full list of author information is available at the end of the article
}

life events, and educational debt $[1,2]$. While stress can play an adaptive role in providing that extra motivation and "push" in times of intense study, if left unidentified or unmanaged, stress may manifest in detrimental ways such as impaired sleep and appetite, symptoms of depression and anxiety, and at worst, suicide [3-5]. This may result in downstream consequences such as poor academic performance, cynicism, academic dishonesty, and/or substance abuse. Heightened stress contributes to roughly $25 \%$ of medical students considering dropping out [4]. What's more is that only roughly $16 \%$ of medical students who screen positive for depression actually seek psychiatric treatment [5]. In order to create sustainable original author(s) and the source, provide a link to the Creative Commons licence, and indicate if changes were made. The images or other third party material in this article are included in the article's Creative Commons licence, unless indicated otherwise in a credit line to the material. If material is not included in the article's Creative Commons licence and your intended use is not permitted by statutory regulation or exceeds the permitted use, you will need to obtain permission directly from the copyright holder. To view a copy of this licence, visit http://creativecommons.org/licenses/by/4.0/. The Creative Commons Public Domain Dedication waiver (http://creativeco mmons.org/publicdomain/zero/1.0/) applies to the data made available in this article, unless otherwise stated in a credit line to the data. 
interventions, it is crucial to effectively measure medical student stress in the most precise way possible.

While global measurement tools exist to assess stress or burnout, such as the Perceived Stress Scale (PSS) and Maslach Burnout Inventory (MBI), they are designed for use across broad populations and do not capture the specific experience of medical students. For student populations in general, multiple scales have been created to gauge stress levels; however, each comes with limitations and are not ideal for use within medical student populations. For example, the Student-Life Stress Inventory (SSI) has a significant focus on physical stress responses and universally stressful scenarios, and the combination of stress factors experienced specifically by medical students is not represented by its broader items [6]. Other student stress scales such as the Undergraduate Stress Questionnaire (USQ) and the Scale for Assessing Academic Stress (SAAS) are not designed for the context of medical students $[7,8]$. Other metrics, such as the Perception of Academic Stress Scale (PAS), are focused on test anxiety and were developed to test stress levels in courses where grades depended primarily on a singular exam [9]. The stressors of medical school encompass far more than the stress of an individual exam. For medical student stress specifically, three different measures exist, each with its own limitations; Perceived Medical Student Stress (PMSS) Instrument [10], Medical Student Stress Profile (MSSP) [11], and Medical Student Stressor Questionnaire (MSSQ) [12]. The PMSS is a 13-item measure containing several items that can be considered double-barreled (e.g., they measure two or more different things), such as "Medical school is cold, impersonal and needlessly bureaucratic." Several items are also negatively phrased, which can be cognitively complex to understand when double negatives occur. Finally, it includes certain colloquialisms (e.g., "baptism by fire") that may not be fully understood by all respondents. The MSSP is a 52-item measure, which, in addition to its length (and associated response burden) also instructs respondents to rate each item twice; once to measure how true the item is, and then to measure how stressful it is. This can create unnecessary cognitive load and response burden as it actually requires a respondent to answer 102 items. Finally, the MSSQ is either a 20 or 40 British English item measure that contains a list of possible stressors, versus items that are written in a more common question or statement form (e.g., "heavy workload", "large amount of content to be learnt", "falling behind in reading schedule"). A list of issues is not necessarily a limitation in and of itself, however, given the nature of medical student stress, a respondent may more easily and quickly identify with an item's content and meaning when it is written in a more personal way.
Given these shortcomings, the purpose of this current study was to use established measurement development methodologies based on the Patient Reported Outcomes Measurement Information System ${ }^{\circledR}$ (PROMIS) [13] to develop and test a new measure of medical student stress.

\section{Methods \\ Overview}

This study was approved by the participating institution's internal review board. The development and testing of this new measure drew from a widely accepted multistep, multi-phase measurement development methodology based on the PROMIS methodology, which included the following: PHASE I: 1) A literature search of existing measures, concepts, and items; 2) Development of a guiding conceptual framework; 3) Medical student group discussions to elucidate and confirm important concepts and issues related to medical student stress; 4) Creation of an initial pool of medical student stress items; 5) Refinement of items via expert review; 6) Cognitive interviews with medical students; and 7) Final expert item review; PHASE II: The final item pool was administered to a sample of actively enrolled medical students attending a large, private Midwestern university, with an average class size of 160 students (total number of enrolled students was roughly 640 students). Given that PHASE I activities have been previously reported [14] this report will focus exclusively on PHASE II activities. Overall study flow is graphically represented in the supplementary online material (Additional file 1: Figure-SF1).

\section{Calibration testing procedures}

Eligible participants were current medical students (1st - 4th year also known as "M1-M4") at the participating institution. Inclusion criteria for participants included students in either the MD or MD/PhD programs actively enrolled in coursework and/or clinical rotations. Exclusion criteria included $\mathrm{MD} / \mathrm{PhD}$ students in the research portion of their program. There were no power calculations used to determine sample size. We attempted to enroll $>200$ eligible participants who represented the target population. Following informed consent, the authors administered a $10-15 \mathrm{~min}$ online survey via Research Electronic Data Capture (REDCap), which is a secure web-based data collection application. Participation was voluntary and responses were kept anonymous. Secure invitations were sent via an encrypted email service, and survey participants were notified that taking part in the survey would have no bearing on academic standing whatsoever. 


\section{Measures}

In addition to new items of medical student stress, the authors also administered the following socio-demographic form and legacy measures to establish preliminary convergent validity evidence: 1) Socio-Demographic Form: This included year in medical school, gender, race (either Caucasian or non-Caucasian), and religious belief; 2) Health and Lifestyle Behaviors. Using single-item statements with a 5-point Likert response scale, the authors asked participants about their sleep and exercise patterns, including questions on frequency of exercise, average total hour of sleep per night, and impact from sleep and exercise on stress; 3) Burnout. To measure burnout, the authors administered the 10-item Burnout Measure Short Version [15]; 4) Perceived Stress. To gauge stress levels, the authors used the Perceived Stress Scale-4 (PSS-4) [16]; 5) Anxiety. To assess anxiety, the authors used the 4-item PROMIS Anxiety Short Form, which was drawn from a 29-item bank [17]; 6) Visual Analog Scale (VAS). To assess current stress levels, the authors used a VAS in the form of a single question which asked participants to rate their perceived stress levels on a 10-point Likert-type scale ranging from no stress at all (1) to worst stress imaginable (10). See Table 1 for the validity measure characteristics (domains, number of items, and reliabilities) used in this study.

\section{Analysis}

Following data cleaning, the authors first conducted a series of exploratory item factor analyses (EFAs), including unidimensional, 2- and 3-Factor solutions. Consistent with previous studies, we used a combination of statistical factor enumeration strategies and theory [18]. The number of factors to extract was guided by the theoretical model utilized when developing the questionnaire. Targeted EFA rotations allowed the authors to explore these theoretical models of stress and burnout (e.g. reasons, reactions, and responses to stress). The optimal model was chosen based off of a combination of model fit (utilizing the Akaike and Bayesian Information Criteria [AIC and BIC, respectively], and Velicer's minimum average partial [MAP] test, all of which favor models with lower values) and interpretability of the factor solution.

The optimal model was then fit using a confirmatory item factor analysis (CFA), and used for reliability and validity evaluations. If significant differences emerged between the EFA and CFA results, further item and scale refinement occurred. Then, we used item response theory (IRT) for scoring. The final items were calibrated using the graded response model [19]. Given that our theoretical model suggested potential multidimensionality, we did not restrict the GRM to the unidimensional case but would allow multidimensional IRT if indicated from the EFA and CFA results. Other IRT assumptions were also evaluated, including visual inspection of responses of non-parametric response curves for monotonicity and inspection of specific-factor loadings and residuals from the CFA results to examine local dependence.

Cronbach's alpha and McDonald's omega was used to index internal consistency reliability, and Pearson correlation coefficients with external measures were used to index validity. T-scores derived from the optimal model were also used in known group's discriminant validity t-test evaluations. The authors hypothesized that the optimal model for the MSSS would exhibit high internal consistency $(\alpha>0.80)$, and correlate moderately with validity measures $(r>0.50)$ [20]. The authors also hypothesized that there would be at least a small observed effect size difference $(\mathrm{d}>0.20)$ between known groups.

\section{Results}

Following all item development activities, the authors arrived at a field testing-ready item pool of 35 items. The item context for all items is "Since starting medical school" with response options: $0=$ Never, $1=$ Rarely, $2=$ Sometimes, $3=$ Often, and $4=$ Always.

\section{Calibration testing results}

In total, 348 medical students completed the survey $(\mathrm{M} 1=144$ (41\%), M2 = 145 (42\%), M3 = 26 (7\%), M4=33 (9\%)), of which 175 (50\%) were male and 173 (50\%) were female. In terms of ethnicity, 197 (57\%) responded white/

Table 1 Validity measure characteristics

\begin{tabular}{|c|c|c|c|c|}
\hline & Dimensions & Number of items & Score range & $\begin{array}{l}\text { Reliability } \\
\text { (Cronbach's } \\
\text { a) }\end{array}$ \\
\hline Burnout Measure [15] & Emotional Exhaustion & 10 & $1-7$ & $0.85-0.87$ \\
\hline PROMIS Anxiety-4 [17, 22] & $\begin{array}{l}\text { Fear, anxious misery, hyperarousal, and somatic } \\
\text { symptoms related to arousal }\end{array}$ & 4 & $4-20$ & 0.93 \\
\hline Perceived Stress-4 [23] & Perceived Stress & 4 & $0-16$ & 0.77 \\
\hline Visual Analog Scale & Current Stress Level & 1 & $1-10$ & $\mathrm{n} / \mathrm{a}$ \\
\hline
\end{tabular}


Caucasian, 155 (45\%) responded non-Caucasian, and 2 (1\%) did not respond.

As is typical with factor enumeration, indices did not provide clear support for the same number of factors. The AIC and BIC favored a 3-factor solution (1-factor AIC 95\% CI 29733-29,734 BIC 30403-30,405; 2-factor AIC 29284-29,286 BIC 30085-30,087; 3-factor AIC 29124-29,126 BIC 30053-30,055), while the MAP slightly favored the 2-factor solution (1-factor 0.014; 2 -factor 0.010 ; 3-factor 0.011 ). As the 3-factor model was more consistent with the theoretical model, the authors selected this model and labeled the factors: 1) Social Challenges; 2) High Activation; and 3) Low Activation. The Social Challenges factor represented items such as difficulty asking for help, feeling unsupported by faculty and peers, feeling taken advantage of by faculty, and feeling pressure to get good grades. The High Activation factor represented items such as feeling anxious, being unable to relax, being overly self-critical, and feeling overwhelmed. Finally, the Low Activation factor represented items such as feeling hopeless, depressed, having difficulty motivating oneself, and feeling like dropping out of school. See Table 2 below for item coefficients by factor. Note that generally, item coefficients $>.30$ characterize each respective factor, however in the case of cross-loadings (due to conceptual overlap), the higher coefficient is to be used.

The authors removed two items that did not load well on any factor (e.g., stress about finances and exercising less), as well as two items with negative cross loadings (e.g., pressure to get good grades and need to be perfect). The authors retained other items with cross-loadings if they were conceptually/clinically relevant for content validity. It is important to note that while there are plausible 3-factors, they are not necessarily conceptually "separate" and one scale could still give a precise score that encompasses all three.

The authors proceeded with testing a 3-factor solution in a restricted, hierarchical CFA model, allowing cross-loading items to co-load between High and Low Activation. The High and Low Activation factors came to represent locally dependent doublets or triplets (e.g., alcohol \& drugs: msss9 \& msss10; pressure: msss26, msss27, \& msss28; dropping out: msss4, msss34, \& msss35; and feeling unmotivated: msss14 \& msss25), rather than two distinct factors. The authors decided to remove one item in locally dependent pairs and 1-2 items in locally dependent triplets, and remove items with poor remaining relationships, based on content relevance and available item information. The optimal final model was a bi-factor model with a general factor representing stress/burnout and a specific factor with six items (msss2, msss19, msss20, msss21, msss22, msss24) representing both general stress/burnout and social challenges. This is graphically represented in the supplementary online material (Additional file 2: Figure-SF2).

\section{Item calibration using item-response theory modeling}

The retained 22 items underwent item response theory (IRT) bi-factor calibration, which provides specific information about each item's discriminability and performance along a severity continuum from mild to severe. Marginalizing the social challenges factor to emphasize the stress/burnout, the primary factor provided item slopes (e.g., how discriminating each item is), item thresholds (e.g., how difficult each item is in order for a person to endorse a specific response category), marginal item characteristic curves (e.g., a visual depiction of each item's discrimination between response categories and how informative an item is across a continuum), and a test information function (e.g., how informative and precise the entire set of items is across the continuum of the latent trait) [18] . The IRT parameters, marginal item characteristic curves, and marginal information plots, are available as online supplementary material (Additional file 3: Table-ST1).

Figure 1 below illustrates how well the MSSS estimates a respondents' latent trait of medical student stress over the whole range of scores. Since test information function will be much higher than any single item information function, a test measures ability more precisely than does a single item. The MSSS is a reliable scale (Cronbach's $\alpha=0.89$; omega $_{\text {total }}=0.94$; omega hierarchical $=0.91$ ), covers a wide range of medical student stress, and only declines in precision (i.e. reliability) towards the very extremes of stress.

\section{Administering and scoring the MSSS-22}

See Table 5 for MSSS-22 instructions and recall period, response options, and items.

Items from the MSSS-22 may be summed into a total score and converted into a $\mathrm{T}$ Score with a mean of 50 and standard deviation of 10 by using the conversion table are available as online supplementary material (Additional file 4: Table-ST2).

\section{Validity evidence with external validity measures}

Convergent validity was established with moderately high associations with the Burnout Scale Short Version $(\mathrm{r}=0.800, p<.01)$, PROMIS Anxiety $(\mathrm{r}=0.672, p<.01)$, PSS-4 $(\mathrm{r}=0.739, p<.01)$, and a stress visual analog scale $(\mathrm{r}=0.641, p<.01)$ (see Table 3$)$. Criterion-related validity was established with small inverse associations with selfreported regularity of exercise $(\mathrm{r}=-0.261, p<.01)$ and hours of sleep on average $(\mathrm{r}=-0.237, p<.01)$. 
Table 2 Exploratory factor analysis item coefficients

\begin{tabular}{|c|c|c|c|c|c|}
\hline Item ID & $\begin{array}{l}\text { Item (each begins with } \\
\text { "Since starting medical school") }\end{array}$ & Social challenges & High activation & Low activation & Items removed \\
\hline msss1 & I notice fluctuations in appetite. & 0.08 & 0.03 & 0.46 & \\
\hline msss2 & I have difficulty asking for help. & 0.45 & 0.21 & 0.2 & \\
\hline msss3 & I have trouble falling/staying asleep. & -0.02 & 0.24 & 0.38 & $x$ \\
\hline msss4 & I receive less satisfaction from learning. & 0.11 & -0.04 & 0.65 & \\
\hline msss5 & I am unable to relax. & -0.05 & 0.69 & 0.23 & \\
\hline msss6 & I feel anxious. & -0.08 & 0.69 & 0.27 & \\
\hline msss7 & I am unable to enjoy activities outside of classes/rotations. & 0.01 & 0.49 & 0.29 & \\
\hline msss8 & $\begin{array}{l}\text { I feel pressure extracurricular activities (student groups, research, } \\
\text { etc.). }\end{array}$ & 0.2 & 0.37 & -0.11 & $x$ \\
\hline msss9 & I notice that I drink alcohol in excess. & 0.02 & -0.08 & 0.33 & $x$ \\
\hline msss10 & I use drugs in excess (prescription and/or non-prescription). & -0.01 & -0.04 & 0.47 & $x$ \\
\hline msss11 & I feel hopeless that I will ever get my degree. & 0.08 & 0.25 & 0.59 & \\
\hline msss12 & I feel depressed. & 0 & 0.32 & 0.61 & \\
\hline msss13 & I am stressed about finances. & 0.17 & 0.07 & 0.28 & $x$ \\
\hline msss14 & I have a hard time motivating myself to study. & 0.18 & -0.06 & 0.62 & \\
\hline msss15 & I feel emotionally exhausted. & 0.11 & 0.46 & 0.38 & \\
\hline msss16 & $\begin{array}{l}\text { I feel bothered by the amount of exposure to death and human } \\
\text { suffering. }\end{array}$ & 0.3 & 0.06 & 0.17 & $x$ \\
\hline msss17 & I am fearful of failing. & 0.13 & 0.52 & 0.28 & \\
\hline msss18 & I exercise less. & 0.18 & 0.18 & 0.15 & $x$ \\
\hline msss19 & I feel unsupported by my peers. & 0.54 & 0.18 & 0.09 & \\
\hline msss 20 & I feel competition from my peers. & 0.54 & 0.29 & -0.19 & \\
\hline msss 21 & I feel unsupported by faculty. & 0.8 & -0.09 & 0.16 & \\
\hline msss 22 & $\begin{array}{l}\text { I feel taken advantage of by faculty (i.e. research mentors, profes- } \\
\text { sors, and/or school administrators). }\end{array}$ & 0.68 & -0.1 & 0.02 & \\
\hline msss23 & $\begin{array}{l}\text { It is challenging to maintain relationships with others outside of } \\
\text { school. }\end{array}$ & 0.08 & 0.34 & 0.19 & $x$ \\
\hline msss 24 & $\begin{array}{l}\text { I feel pressure from others (parents, professors, mentors, etc) to } \\
\text { get good grades. }\end{array}$ & 0.39 & 0.23 & 0.06 & \\
\hline msss 25 & I feel unmotivated to attend class. & 0.18 & -0.06 & 0.41 & $x$ \\
\hline msss 26 & I feel pressure from myself to get good grades. & 0.1 & 0.71 & -0.38 & $x$ \\
\hline msss27 & I am overly self-critical. & -0.01 & 0.85 & -0.03 & \\
\hline msss 28 & I feel need to be perfect. & 0.2 & 0.77 & -0.29 & $x$ \\
\hline msss 29 & I am unsure of abilities as student. & 0.07 & 0.49 & 0.36 & \\
\hline msss30 & I hardly have enough time to get things done. & -0.04 & 0.41 & 0.32 & \\
\hline msss31 & I feel overwhelmed by everything there is to do. & 0.01 & 0.53 & 0.43 & \\
\hline msss32 & I struggle maintaining a healthy school-life balance. & 0.15 & 0.59 & 0.16 & \\
\hline msss33 & It is challenging to start or maintain romantic relationships. & 0.12 & 0.31 & 0.19 & $x$ \\
\hline msss34 & I think about dropping out of school. & 0.09 & 0 & 0.79 & \\
\hline msss35 & I question my decision to enter medical school. & 0.15 & -0.05 & 0.76 & $x$ \\
\hline
\end{tabular}

Coefficients in bold characterize respective factors; correlations between factors High Activation and Social Challenges $=.42 ;$ correlation between factors Low Activation and Social Challenges = .36; Correlation between factors Low Activation and High Activation $=.31$. Due to conceptual and psychometric misfit (e.g., model explained less variance/greater error in ratings) we removed items found in the "Items Removed" column. As before, each item stem has the same contextual qualifier - "Since starting medical school"

Known Groups validity was established with statistically significant differences in the MSSS scores between M1s and M2s, and also between male and female medical students (Table 4). Given the more complete samples for M1s and M2s, known groups validity focused on these cohorts as opposed to M3s and M4s with less complete samples. Other validity measures, such as the burnout measure short version and PSS-4, were unable to significantly differentiate difference between M1s and M2s; however, the Burnout Measure was also able to 


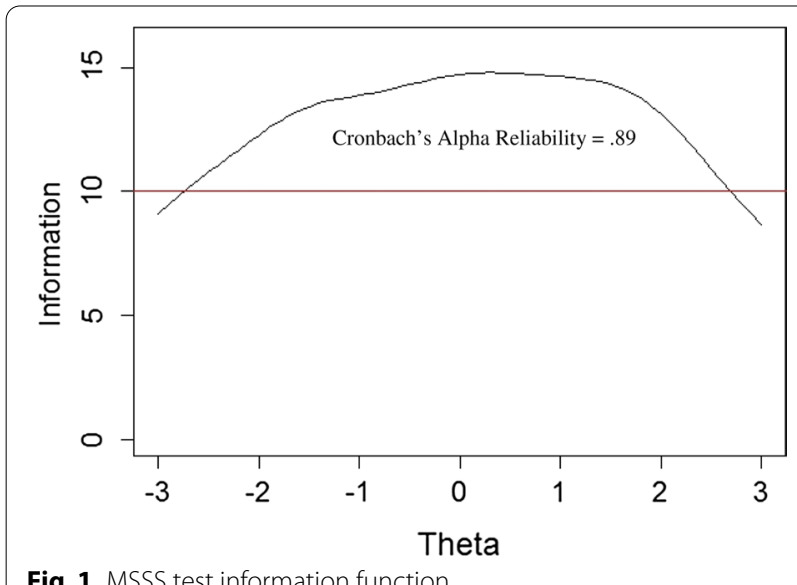

Fig. 1 MSSS test information function

Table 3 Associations between MSSS \& validity measures

\begin{tabular}{ll}
\hline & MSSS \\
\hline Burnout measure & $.800^{\mathrm{a}}$ \\
PROMIS anxiety-4 & $.672^{\mathrm{a}}$ \\
Perceived stress-4 & $.739^{\mathrm{a}}$ \\
Visual analog scale (current stress) & $.641^{\mathrm{a}}$ \\
Regularity of exercise & $-.261^{\mathrm{a}}$ \\
Hours of sleep on average & $-.237^{\mathrm{a}}$ \\
\hline
\end{tabular}

a Correlation is significant at the 0.01 level (2-tailed).

demonstrate a significant difference between male and female students (Table 4).

\section{Discussion}

The purpose of this current study was to gather psychometric evidence for a new measure of medical student stress. The items comprising the MSSS are a distinctive mix of targeted and generic content that encapsulates the experience of stress in the medical school environment. The MSSS was developed using a rigorous, studentcentered methodology that involved medical students, faculty, and experts in medical education, clinical psychology, and measurement development. Field-testing of the final item pool and external validity measures was conducted during required class time, so as not to burden the students' busy schedules.

This study followed a well-established methodology of evaluating a scale's dimensionality using multiple methods including exploratory item factor analysis and interpretability of resulting models by experts in the field. We then further refined the factor model using confirmatory item factor modeling, which showed that most of the potential multidimensionality was likely driven by item doublets and triplets, which may reflect local dependencies. Items were removed in these cases, to further meet the expectations for the third phase of quantitative modeling: IRT. However, multidimensionality in the MSSS remained, insofar as six items reflected social challenges experienced by medical students. This was modeled using a bi-factor IRT model. The final model had 22 items, of which 14 reflected only the general medical social stress and 8 also captured social challenges.

The MSSS is a flexible and precise measure of the different types and levels of stress commonly experienced by medical students. While the MSSS can discriminate very well between those who are experiencing medical student-related stress at varying levels of severity, some precision may decline among individuals experiencing very little stress, as well as for those at extreme levels. Additionally, the MSSS is able to detect statistically significant differences in stress levels between male and female medical students, as well as between first and second year medical students. In some situations, such as medical student year, the MSSS detected differences where other commonly used measures did not. Further, the MSSS demonstrated convergent validity evidence through high, significant associations with the existing measures of burnout, anxiety, and stress.

Our study was not without limitations. The sample was relatively small and drawn from just one institution. Additionally, all models were fit to the same dataset, including the exploratory use of CFA modeling, which limits the results. There were relatively fewer M3 and M4 students, who are known to experience comparatively higher levels of stress compared with M1s and M2s. Over $80 \%$ of participants were M1s and M2s, a discrepancy largely due to increased workload and minimal required

Table 4 Known-groups validity

\begin{tabular}{|c|c|c|c|c|c|c|}
\hline & \multicolumn{2}{|c|}{ Medical student year } & \multirow[b]{3}{*}{ Sig (p) } & \multicolumn{2}{|l|}{ Gender } & \multirow[b]{3}{*}{$\begin{array}{l}\text { Sig } \\
\text { (p) }\end{array}$} \\
\hline & M1 $(n=144)$ & M2 $(n=145)$ & & Male $(n=174)$ & Female $(n=173)$ & \\
\hline & Mean & Mean & & Mean & Mean & \\
\hline MSSS & 50.95 & 48.53 & 0.03 & 47 & 52.5 & $<0.01$ \\
\hline Burnout measure & 32.5 & 30.9 & 0.151 & 2.9 & 3.4 & $<0.01$ \\
\hline PSS-4 & 10.5 & 10.8 & 0.196 & 10.6 & 10.6 & 0.96 \\
\hline
\end{tabular}


Table 5 MSSS scale instructions, recall period, items, and response options

\begin{tabular}{|c|c|}
\hline Instructions \& recall period: & $\begin{array}{l}\text { The questions in this scale ask about your well-being since starting medical school. In each } \\
\text { case, please indicate your response. }\end{array}$ \\
\hline Response options: & $0=$ Never, $1=$ Rarely, $2=$ Sometimes, $3=$ Often, $4=$ Always \\
\hline 1. Since starting medical school, & I notice fluctuations in my appetite. \\
\hline 2. Since starting medical school, & I have difficulty asking for help. \\
\hline 3. Since starting medical school, & I receive less satisfaction from learning new material. \\
\hline 4. Since starting medical school, & I am unable to relax. \\
\hline 5. Since starting medical school, & I feel anxious. \\
\hline 6. Since starting medical school, & I am unable to enjoy activities outside of classes/rotations. \\
\hline 7. Since starting medical school, & I feel hopeless that I'll ever get my degree. \\
\hline 8. Since starting medical school, & I feel depressed. \\
\hline 9. Since starting medical school, & I have a hard time motivating myself to study \\
\hline 10. Since starting medical school, & I feel emotionally exhausted. \\
\hline 11. Since starting medical school, & I am fearful of failing. \\
\hline 12. Since starting medical school, & I feel unsupported by my peers. \\
\hline 13. Since starting medical school, & I feel competition from my peers. \\
\hline 14. Since starting medical school, & I feel unsupported by faculty. \\
\hline 15. Since starting medical school, & I feel taken advantage of by faculty (i.e. research mentors, professors, and/or school administrators). \\
\hline 16. Since starting medical school, & I feel pressure from others (i.e. parents, professors, mentors, etc.) to get good grades. \\
\hline 17. Since starting medical school, & I am overly self-critical. \\
\hline 18. Since starting medical school, & I feel unsure of my abilities as a student. \\
\hline 19. Since starting medical school, & I hardly have enough time to get things done. \\
\hline 20. Since starting medical school, & I feel overwhelmed by everything there is to do. \\
\hline 21. Since starting medical school, & I struggle maintaining a healthy school-life balance. \\
\hline 22. Since starting medical school, & I think about dropping out of school. \\
\hline
\end{tabular}

group class time during third and fourth years to administer the survey. Additionally, given that the survey was optional for all participants, there is the possibility of a selection bias, with the extremes (either most or least stressed) students opting in or out. These factors may have implications on the generalizability of findings.

Future studies will benefit from confirming the proposed factor structure in a new sample, and evaluating its sensitivity to change over time. This is especially important considering possible uses of the MSSS include continuous screening and stress monitoring, as well as to evaluate the effectiveness of wellness interventions to reduce and manage stress in medical school. Since at this time no cut-points have been established to determine thresholds for mild, moderate, and severe levels of stress, future studies should also engage in standard setting activities to facilitate the clinical utility of this tool [21]. Lastly, when viewed on the basis of individual items, the MSSS may appear appropriate for any graduate student; however, when viewed in its 22-item totality, the MSSS represents the multifaceted elements of medical student stress and future testing alongside other student stress scales may help to elucidate further appropriateness for other student groups.

\section{Conclusion}

The 22 items comprising the MSSS are an appropriate blend of specific and generic content relevant to medical student daily life and are supported by a high internal consistency and convergent /concurrent validity. The MSSS can provide accurate, precise, and relevant measurement of stress and burnout for the twenty-first century medical student. Future applications include use as an outcome measure in comparative effectiveness research or as a screening tool in an academic or clinical program.

\section{Practice points}

- Medical students face unique and significant stressors

- Brief and precise measurement of medical student stress is paramount to identifying and ameliorating challenges

- Existing measures have limitations

- The MSSS-22 is a brief, IRT-derived measure with high relevance and precision 
- The MSSS-22 performs as expected with legacy measures and discriminates well between specific groups

\section{Supplementary Information}

The online version contains supplementary material available at https://doi. org/10.1186/s12955-020-01637-0.

Additional file 1. Figure SF1. Study Flow
Additional file 2. Figure SF2. Bifactor Model

Additional file 3. Table ST1. Marginal IRT Parameters with Plots for Item Characteristic Curves and Item Information Curves

Additional file 4. Table ST2. Item Response Theory-Derived T-Score Conversion Table

\section{Abbreviations}

IRT: Item response theory; MSSS: Medical Student Stress Scale; PSS: Perceived Stress Scale; MBI: Maslach Burnout Inventory; PMSS: Perceived Medical Student Stress; MSSP: Medical Student Stress Profile; MSSQ: Student Stressor Questionnaire; PROMIS: Patient Reported Outcomes Measurement Information System ${ }^{\circledR}$; VAS: Visual Analog Scale; EFA: Exploratory factor analysis; CFA: Confirmatory item factor analysis; REDCap: Research Electronic Data Capture.

\section{Acknowledgements}

The authors would like to thank the Augusta Webster Office of Medical Education at Northwestern University's Feinberg School of Medicine, the Osher Center for Integrative Medicine, and Feinberg School of Medicine medical students.

\section{Authors' contributions}

MM assisted in scale development, administered focus groups, administered surveys, and led organization of manuscript. DV led scale development, assisted with organization of manuscript, and oversaw data analysis and synthesis of final scale creation. AK analyzed and interpreted the data and led statistical analyses. MR and GA assisted with item development for stress scale, provided expert feedback on study methodology, and assisted with synthesis of final manuscript. SG assisted with amalgamation of final manuscript. The authors read and approved the final manuscript.

\section{Funding}

None.

\section{Availability of data and materials}

The datasets used and/or analyzed during the current study are available from the corresponding author on reasonable request.

\section{Ethics approval and consent to participate}

Ethical approval: All procedures performed in studies involving human participants were in accordance with the ethical standards of the institutional and/ or national research committee and with the 1964 Helsinki declaration and its later amendments or comparable ethical standards. Approval for project involving human subjects granted on8/19/2014 by Northwestern University's Institutional Review Board Office, IRB project number-STU00092019, review type-exempt (human subjects involved only in surveys, tests, interviews, or observations), protocol sites-Northwestern University (NU) Chicago medical campus. Informed consent: Informed consent was obtained from all individual participants included in the study, including consent for publication.

\section{Consent for publication}

Informed consent for publication was obtained from all individual participants included in the study prior to administration of survey.

\section{Competing interests}

The authors declare that they have no competing interests.

\section{Author details}

${ }^{1}$ Department of Psychiatry, Brigham and Women's Hospital, Harvard Medical School, 60 Fenwood Avenue, Boston, MA 02115, USA. ${ }^{2}$ Department of Medical Social Sciences, Northwestern University Feinberg School of Medicine, Chicago, IL, USA. ${ }^{3}$ Osher Center for Integrative Medicine, Northwestern University Feinberg School of Medicine, Chicago, IL, USA. ${ }^{4}$ Department of Medical Education and Department of Psychiatry and Behavioral Sciences, Northwestern University Feinberg School of Medicine, Chicago, IL, USA.

Received: 20 April 2020 Accepted: 2 December 2020

Published online: 02 January 2021

\section{References}

1. Dyrbye LN, Thomas MR, Shanafelt TD. Medical student distress: causes, consequences, and proposed solutions. Mayo Clin Proc. 2005;80(12):1613-22.

2. Vyas KS, Stratton TD, Soares NS. Sources of medical student stress. Educ Health (Abingdon). 2017;30(3):232-5.

3. Hammen C. Stress and depression. Annu Rev Clin Psychol. 2005;1:293-319.

4. Iorga M, Dondas C, Zugun-Eloae C. Depressed as freshmen, stressed as seniors: the relationship between depression, perceived stress and academic results among medical students. Behav Sci (Basel). 2018;8(8).

5. Rotenstein LS, Ramos MA, Torre M, Bradley Segal J, Peluso MJ, Guille C, et al. Prevalence of depression, depressive symptoms, and suicidal ideation among medical students: a systematic review and meta-analysis. JAMA. 2016;216(21):2214-36.

6. Gadzella BM. Student-life stress inventory: identification of and reactions to stressors. Psychol Rep. 1994;74(2):395-402.

7. Crandall CS, Preisler JJ, Aussprung J. Measuring life event stress in the lives of college students: the undergraduate stress questionnaire (USQ). J Behav Med. 1992;15(6):627-62.

8. Sinha UK, Shrama V, Nepal MK. Development of a scale for assessing academic stress: a preliminary report. J Inst Med. 2007;23(1).

9. Bedewy D, Gabriel A. Examining perceptions of academic stress and its sources among university students: the perception of academic stress scale. Health Psychol Open. 2015;2(2):2055102915596714.

10. Vitaliano PP, Maiuro RD, Mitchell E, Russo J. Perceived stress in medical school: resistors, persistors, adaptors and maladaptors. Soc Sci Med. 1989;28(12):1321-9.

11. O'Rourke M, Hammond S, O'Flynn S, Boylan G. The medical student stress profile: a tool for stress audit in medical training. Med Educ. 2010;44(10):1027-37.

12. Yusoff MSB, Rahim AFA, Yaacob MJ. The development and validity of the medical student stressor questionnaire (MSSQ). ASEAN J Psych. 2010;11(1):13-24.

13. Fries JF, Bruce B, Cella D. The promise of PROMIS: using item response theory to improve assessment of patient-reported outcomes. Clin Exp Rheumatol. 2005;23(5 Suppl 39):S53-7.

14. Mosquera M, Ring M, Agarwal G, Cook K, Victorson D. Development and psychometric properties of a new measure of medical student stress: the medical stress scale 10 (MSSS-10). J Altern Complement Med. 2016;22(6):A114.

15. Malach-Pines A. The burnout measure, short version. Int J Stress Manag. 2005;12(1):10.

16. Cohen S, KamarckT, Mermelstein R. A global measure of perceived stress. J Health Soc Behav. 1983;24(4):385-96.

17. Pilkonis PA, Choi SW, Reise SP, Stover AM, Riley WT, Cella D, et al. Item banks for measuring emotional distress from the patient-reported outcomes measurement information system (PROMIS(R)): depression, anxiety, and anger. Assessment. 2011;18(3):263-83.

18. Ye ZJ, Liang MZ, Li PF, Sun Z, Chen P, Hu GY, et al. New resilience instrument for patients with cancer. Qual Life Res. 2018;27(2):355-65.

19. Stucky BD, Thissen D, Orlando Edelen M. Using logistic approximations of marginal trace lines to develop short assessments. Appl Psychol Measur. 2012;37(1):41-57.

20. Cohen J. A power primer. Psychol Bull. 1992;112(1):155-9.

21. Cook KF, Victorson DE, Cella D, Schalet BD, Miller D. Creating meaningful cut-scores for Neuro-QOL measures of fatigue, physical functioning, and 
sleep disturbance using standard setting with patients and providers. Qual Life Res. 2015;24(3):575-89.

22. Riley WT, Rothrock N, Bruce B, Christodolou C, Cook K, Hahn EA, et al. Patient-reported outcomes measurement information system (PROMIS) domain names and definitions revisions: further evaluation of content validity in IRT-derived item banks. Qual Life Res. 2010;19(9):1311-21.

23. Warttig SL, Forshaw MJ, South J, White AK. New, normative, English-sample data for the short form perceived stress scale (PSS-4). J Health Psychol. 2013;18(12):1617-28.

\section{Publisher's Note}

Springer Nature remains neutral with regard to jurisdictional claims in published maps and institutional affiliations.
Ready to submit your research? Choose BMC and benefit from:

- fast, convenient online submission

- thorough peer review by experienced researchers in your field

- rapid publication on acceptance

- support for research data, including large and complex data types

- gold Open Access which fosters wider collaboration and increased citations

- maximum visibility for your research: over 100M website views per year

At BMC, research is always in progress.

Learn more biomedcentral.com/submissions 